\section{Commentary: When misdiagnosis leads to silver lining - a simple solution to the complex problem of congenital coronary artery fistula}

\author{
Gabor Bagameri, MD, and Juan A. Crestanello, MD
}

In the current manuscript, the authors describe the surgical repair of a distal coronary artery fistula (type B) to the right ventricle by simple outflow closure and long-term anticoagulation that was misdiagnosed as an apical ventricular septal defect on preoperative echocardiogram. ${ }^{1}$ Coronary artery fistula (CAF) is a congenital $(>90 \%)$ or acquired abnormal vascular communication of coronary arteries with cardiac chambers or any segment of the systemic or pulmonary circulation, without an intervening capillary network. Congenital CAFs can be isolated or complex, depending on whether they are associated with other congenital heart diseases. CAFs account for $0.3 \%$ of congenital heart diseases.

Most patients with congenital CAFs are asymptomatic due to the small size of the fistula, but CAFs can present with a variety of manifestations. Patients with CAFs usually have a continuous murmur-compared with the holosystolic murmur of ventricular septal defect-and differential diagnoses include persistent ductus arteriosus, pulmonary arteriovenous fistula, and ruptured sinus of Valsalva aneurysm.

The clinical presentations are usually progressive exertional shortness of breath and that of heart failure due to left to right shunt as described in the case report. CAFs can also alter coronary hemodynamics, and patients can present with angina and/or cardiomyopathy. The lowpressure sink of the fistula results in preferential flow

From Cardiovascular Surgery, Mayo Clinic, Rochester, Minn.

Disclosures: The authors reported no conflicts of interest.

The Journal policy requires editors and reviewers to disclose conflicts of interest and to decline handling or reviewing manuscripts for which they may have a conflict of interest. The editors and reviewers of this article have no conflicts of interest.

Received for publication Feb 19, 2020; revisions received Feb 19, 2020; accepted for publication Feb 20, 2020; available ahead of print March 5, 2020.

Address for reprints: Juan A. Crestanello, MD, Mayo Clinic, 200 First St SW, JO5200, Rochester, MN 55905 (E-mail: Crestanello.Juan@mayo.edu).

JTCVS Techniques 2020;2:75-6

2666-2507

Copyright (C) 2020 The Authors. Published by Elsevier Inc. on behalf of The American Association for Thoracic Surgery. This is an open access article under the CC BY-NCND license (http://creativecommons.org/licenses/by-nc-nd/4.0/).

https://doi.org/10.1016/j.xjtc.2020.02.032

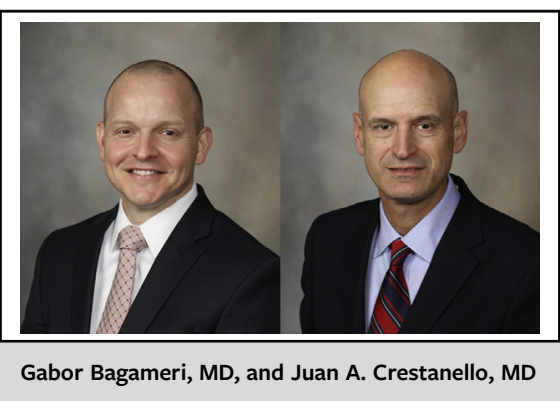

\section{CENTRAL MESSAGE \\ Coronary artery fistula is an un- common coronary artery ab- normality for which proper diagnosis and clinical expertise are critical for good outcomes. It should be treated in a heart team approach.}

through it and it can produce a coronary steal phenomenon in the distal native coronary artery. The coronary artery tends to undergo significant dilation proximal to the fistula, but this may not compensate for the steal. ${ }^{2}$

Conventional coronary angiography is the gold standard for the assessment and diagnosis of CAFs. It only provides 2-dimensional images, which can be of limited value in large, tortuous, complex fistula of overlapping anatomy. Computed tomography imaging with 3-dimensional coronary reconstruction can help to delineate the complex anatomy of fistula and to guide therapeutic interventions. Transthoracic or transesophageal echocardiography can also be used to make the diagnosis of CAFs. The use of contrast material can facilitate more precise determination of the anatomy and extent of CAFs. Echocardiography can provide valuable hemodynamic information, but it is highly operator dependent and relies on the proper acquisition and interpretation of the data. ${ }^{3}$

Coronary artery fistulas can be closed by surgical methods or transcatheter techniques. The existing guidelines do not indicate a preference for either route. Surgical repair can be performed with or without cardiopulmonary bypass and with or without concomitant bypass. Multiple surgical techniques have been applied, including epicardial ligation with or without actual division of the fistula or closure by a transcoronary, through a cardiac chamber (transcameral), or transpulmonary approach. ${ }^{4}$ 
Postoperative myocardial infarction can occur because of low flow in the dilated coronary artery proximal to fistula closure. The awareness and recognition of this phenomenon is of paramount importance, as it mandates immediate anticoagulation. The recommended duration of anticoagulation is 6 to 12 months. This allows enough time for the native coronary to remodel and for flow to normalize, at which point anticoagulation can be discontinued.

\section{References}

1. Albacker T, Barghouthi R, Zahran F, Aljerayed N. Surgical treatment of left main and left anterior descending artery ectasia with fistula to right ventricle. J Thorac Cardiovasc Surg Tech. 2020;2:70-2.

2. Reddy G, Davies J, Holmes D, Schaff H, Singh S, Alli O. Coronary artery fistulae. Circ Cardiovasc Interv. 2015;8:e003062.

3. Barbosa M, Katina T, Oliveira H, Neuenschwander F, Oliveira E. Doppler echocardiographic features of coronary artery fistula: report of 8 cases. $J$ Am Soc Echocardiogr. 1999;12:149-54.

4. Said S, Burkhart H, Schaff H, Connolly H, Phillips S, Suri R, et al. Late outcome of repair of congenital coronary artery fistulas-a word of caution. J Thorac Cardiovasc Surg. 2013;145:455-60. 